\title{
EL ARTE DE LO ÍNTIMO \\ Y LA CREACIÓN DE UN MUNDO COMÚN ${ }^{1}$
}

\section{THE ART OF INTIMACY AND THE CREATION OF A COMMON WORLD}

\author{
Sabine FORERO-MENDOZA \\ Universidad de Pau et des Pays de l'Adour \\ sabine.forero-mendoza@univ-pau.fr
}

Resumen: A partir de mediados de los años 90, en el campo la práctica artística, se multiplican las obras que hacen de la exploración de la intimidad un tema mayor donde lo más fútil de la existencia cotidiana se convierte en el material predilecto. Muchas críticas estigmatizan el narcisismo de una sociedad despolitizada y sometida al imperativo de la transparencia. Tomando una dirección opuesta, este artículo trata de mostrar que algunos artistas, al expresar aspectos de sus vidas íntimas, alcanzan a definir un mundo común propicio para el despliegue de interrogaciones políticas y sociales.

Palabras clave: Íntimo. Arte contemporáneo. Mundo común.

Abstract: Since the second half of 1990's, within the artistic practice field, numerous are the works that make the exploration of intimacy a major theme where the most futile in daily existence becomes the favorite material. A lot of critics stigmatize the narcissism of a depoliticized society, submitted to the imperative of transparency. Taking an opposite direction, this article

\footnotetext{
${ }^{1}$ Este artículo se inscribe en el marco del proyecto de investigación franco-español "Figures et frontières de l'intime à l'époque contemporaine / Figuras y fronteras de la intimidad en la época contemporánea" (OPE-2017-0042), de la Universidad de Pau et des Pays de l'Adour EFM (FR 4153), ALTER (EA7504), ITEM (EA 3002) en colaboración con el grupo de investigación "Lenguajes" (HUM 224) de la Universidad de Córdoba (España) y el laboratorio "Arts Plastiques" (EA 7472) de la Universidad de Rennes 2 (Francia).
} 
tries to explain that some artists, while expressing aspects of their intimate lives, succeed in defining a common world convenient for the deployment of political and social interrogations.

Key Words: Intimacy. Contemporary Art. Common world.

En 1994, la artista de origen palestino Mona Hatoum, realiza el vídeo titulado Corps étranger $(11 \mathrm{~min} .51 \mathrm{~s}$.) con la ayuda de una cámara endoscópica que explora alternativamente la superficie de su cuerpo y es introducida en sus diversos orificios. Las imágenes obtenidas son proyectadas bajo una forma circular sobre el suelo de un edículo cilíndrico; una banda sonora emitiendo las pulsaciones cardiacas, tal como las escuchamos desde las diferentes partes del cuerpo examinadas por la cámara, acompaña las imágenes. Invitado a entrar dentro de la pequeña construcción por dos puertas situadas a cada lado, el espectador penetra metafóricamente al interior del cuerpo y comparte la observación autoescópica, hecha por el artista, del funcionamiento habitualmente invisible de algunos de sus órganos. El cuerpo revela su extrañeza, manifiesta incluso para la artista misma, ya que no está permitida la formación de ninguna imagen unificadora o de ningún tipo de identificación narcisista.

Esta realización nos parece representativa de una tendencia observable en el escenario artístico a mediados de los años 90 consistente en hacer de la exploración de la intimidad un tema mayor, en oposición a una importante corriente que había conducido, durante los años 60 y 70, a borrar toda huella de subjetividad en el arte y a afirmar cierta despersonalización como principio creativo (minimalismo, abstracción hard edge, objetividad fotográfica...). El movimiento del péndulo parece haberse invertido: se multiplican los relatos y la puesta en escena de sí mismo, así como las prácticas que buscan instaurar una relación estrecha entre la obra y cada uno de los individuos que conforman su público. Muchas de las creaciones ostentan la marca de lo íntimo: ellas adoptan una perspectiva cercana, se focalizan en pequeños eventos atados a una singularidad individual, hacen de lo más fútil de la existencia cotidiana su material de predilección ${ }^{2}$, como demostró la exposición pionera La sphère

${ }^{2}$ Veánse, por ejemplo, las realizaciones de Joël Bartoloméo, Valérie Pavia, Loïc Connanski, Sylvie 
de l'intime, presentada en el marco del Printemps de Cahors, en 1998, antes de que la literatura crítica se haya apoderado del fenómeno (Thély, 2002; Cauquelin, 2003; Maison Rouge, 2004; Lebovici, 2004; Watteau, 2010; Chiron y Lelièvre, 2012) ${ }^{3}$.

El vídeo de Mona Hatoum llevaría a su paroxismo esta tendencia y, empujando hasta las últimas trincheras la exploración de sí mismo autorizada por las prácticas de la autofilmación, manifestaría su aporía: al adoptar la mirada médica que pretende sondear los repliegues más ocultos del cuerpo, tanto el artista como el espectador no distinguen nada.

Frente a las producciones que pertenecen a la esfera de lo íntimo, se perfilan dos líneas de evaluación contradictorias. La primera se apoya sobre el crédito atribuido a los valores de autenticidad, profundidad y sinceridad, con las cuales se confunde habitualmente lo íntimo. La segunda, más compartida, estigmatiza al contrario una tendencia al narcisismo —más aun al exhibicionismo - que se habría vuelto la norma en unas sociedades despolitizadas, totalmente sometidas a los requerimientos del consumo. Las consecuencias de tales afirmaciones merecen ser cuestionadas. ¿Desaparece lo íntimo con las formas artísticas de su exhibición, contradictorias por definición con su esencia? ¿Las manifestaciones artísticas de lo íntimo impiden, de verdad, la realización de una relación constructiva con el espectador y la posibilidad de despliegue de un mundo común?

\section{LA PUBLICACIÓN DE LO ÍNTIMO}

Antes de contestar a estas preguntas, hay que confrontarse con una paradoja desde el principio. Si lo íntimo nos remite, por su etimología, al superlativo latino intimus y designa así lo más interior, lo más profundo y lo más secreto, no puede existir, en el sentido más amplio, un arte de lo íntimo. ¿Qué imagen o que forma podrían proporcionarse? ¿Y, si se trata efectivamente de volverlas visibles, cómo no destruir en el mismo gesto lo que es situado aparte de la mirada del otro?

Esta contradicción, que parece difícilmente evitable, está sin duda ligada a una aproximación restringida no solamente de lo íntimo, sino también de la creación artística. Una reflexión de Hannah Arendt en

Laliberté, Manon Labrecque, Ana Casas Broda y Annelies Strba.

${ }^{3}$ Para hablar solo de la literatura teórica francesa. 
Condición del hombre moderno nos permite superarla:

La vida íntima es una sombra vaga mientras no se haya transformado (arrancada a lo privado, desindividualizada por decirlo asi) en objetos dignos de aparecer en público. Es la transformación que se produce de ordinario en el relato y generalmente en la transposición artística de las experiencias individuales. Cada vez que describimos las experiencias que no son posibles sino en lo privado o en la intimidad, nosotros las colocamos en una esfera donde ellas toman una especie de realidad que, a pesar de su intensidad, ellas no poseían antes. Es la presencia de los otros mirando lo que nosotros vemos, escuchando lo que nosotros escuchamos, que nos garantiza la realidad del mundo y de nosotros mismos (Arendt, 1961: 90) ${ }^{4}$.

Según Hannah Arendt, la vida íntima no existe sino cuando sus manifestaciones son llevadas fuera y sobre el terreno de lo colectivo. Contrariamente a las ideas recibidas, la riqueza de lo íntimo no está garantizada por el retiro ni la ocultación. Y si existe semejante riqueza, se define solamente a través de una expresión que hace salir al sujeto de sí mismo para que vuelva, más consciente de lo que era antes, gracias al desvío por la mirada o la escucha del otro. Hay que ir contra los usos y, más aun, contra la deriva sugerida por la palabra misma: lo íntimo no designa un espacio que se podría circunscribir y pensar a partir de las oposiciones dentro/fuera, interior/exterior, superficie/profundidad. Hay que rechazar, como indicaba ya Bergson, la aparente estabilidad de las representaciones espaciales. Si se puede caracterizar lo íntimo sin riesgo de hipostasiar, es describiéndolo como una zona de intercambio donde las fronteras están constantemente negociadas y reconfiguradas, a medida de las evoluciones de los estados físicos y de los estados de conciencias, pero también de las representaciones hechas y otorgadas. Por esta razón, Arendt habla de vida íntima (y no de intimidad que significaría un estado) para señalar ese movimiento de ida y vuelta a través del cual nosotros damos consistencia a nuestra propia experiencia y aquella otra del mundo donde vivimos y donde nos situamos. Lo subjetivo de la existencia, en sus dimensiones sensible y pensante, se ahonda solo (si se conserva la imagen

${ }^{4} \mathrm{La}$ traducción es nuestra a partir de la edición francesa. 
de profundidad) en la determinación de un horizonte compartido (lo común en términos de Arendt). No basta con decir que lo íntimo no excluye la exposición, hay que afirmar que la exposición es la condición misma de lo íntimo y que su realidad es representación. Y, si aceptamos esta primera conclusión, debemos reconocer el papel privilegiado de la creación artística en este proceso. La obra artística, en un sentido amplio, es siempre un intento de dar una forma comunicable y transmisible a una intuición, una emoción percibida con fuerza, una visión, en fin, una realidad subjetiva, confusamente distinguida, que solamente toma consistencia y contorno cuando se configura tras las palabras de la tribu - o las formas-, en un esfuerzo para conferir un sentido más puro (Mallarmé). Para decirlo de otra forma, lo íntimo no va sin lo extimo.

Coincidimos aquí con el análisis propuesto por el psicoanalista Serge Tisseron quien designa con el término de extimité — que retoma de Jacques Lacan - "el movimiento que empuja a cada cual a exponer una parte de su vida íntima tanto física como psíquica”. Y añade:

Ese movimiento, que se mantuvo mucho tiempo en silencio, consiste en el deseo de hablar sobre el mundo interior. Pero ese movimiento sería incomprensible si solo se tratara de "expresar" algo. Si la gente quiere exteriorizar ciertos elementos de su vida, es para apropiárselos mejor, interiorizándolos de otro modo gracias a los intercambios que suscitan con sus prójimos. La expresión del soy intimo - que hemos designado bajo el nombre de "extimite"- entra así al servicio de la creación de una intimidad más rica (Tisseron, 2001: 52$)^{5}$.

Elmovimiento de laextimitées descrito comoinherentealmecanismo de la vida psicológica y social del individuo. Las únicas variaciones que le afectan dependen del grado de su valorización ideológica, en función de circunstancias culturales y sociales. Hasta hace poco, apenas se aceptaba la comunicación pública de las emociones, sentimientos y reflexiones interiores, hoy en día, al contrario, se considera como constitutiva de la definición de la persona y del intercambio social. ¿Pero la acentuación sin precedentes del fenómeno en la sociedad postmoderna permite de verdad

${ }^{5}$ La traducción es nuestra. 
la creación de una intimidad más rica como afirma el autor?

\section{UN REPLIEGUE SOBRE SÍ MISMO}

La mayoría de los analistas adoptan una visión diferente y deploran un empobrecimiento. Ellos realzan la progresión de los fantasmas conjugados de la autenticidad y de la visibilidad fundados sobre las ecuaciones erróneas ver es conocer y lo que se muestra es real y ponen en evidencia sus repercusiones: la rareza de las zonas de penumbra y el valor de la exposición, como muestran, a diferentes niveles, el éxito de la prensa del corazón, la multiplicación de los reality shows, el desarrollo exponencial de las páginas personales, los foros de discusión y las redes sociales, la incitación a la confesión pública y el gusto por las confidencias sexuales más crudas y detalladas 6 .

Para describir este proceso, uno se puede situar en el surco de los análisis de Habermas y hablar de la subversión de sociedades de publicidad dominadas por la razón instrumental y un ideal ilusorio de transparencia que, en realidad, no es sino una forma nueva de tiranía y de manipulación. Es como si todo lo que está puesto en el marco de la existencia privada y pertenece a sus dominios más reservados se encontrara aspirado dentro de la esfera pública, expuesto a pleno día. Sus explicaciones son múltiples: se subraya la extrema accesibilidad a las nuevas tecnologías y a los aparatos numéricos de grabación, $\mathrm{o}$, situándose en una perspectiva ideológica, también se puede poner en evidencia el desencanto frente a los valores colectivos o la atomización de las sociedades, ambos responsables del repliegue del individuo sobre sí mismo y su pequeño mundo. Como sustento, se evoca la aceleración del tiempo que incitaría a lanzarse en una búsqueda angustiante de identidad y multiplicar, en una especie de convulsión frenética e histérica, los reflejos y las huellas de sí mismo. Pensadores como Gilles Lipovetsky o Charles Melman, por ejemplo, incriminan el abandono de lo político que entregaría el espacio público a los deseos cambiantes de los individuos transformados en ávidos consumidores de gozos privados ${ }^{7}$. El sujeto carente de una identidad

\footnotetext{
${ }^{6}$ Véase, por ejemplo, La vie sexuelle de Catherine M. de Catherine Millet. Este libro consagrado al relato detallado de su vida libertina, verdadero éxito de librería en 2001, fue traducido a más de 33 idiomas.

${ }^{7}$ Veánse Gilles Lipovetsky (1983) y Charles Melman (2002).
} 
estable vería su imagen difractada en un número de reflejos equivalentes al número de pantallas donde se expone y se mira. Incapaz de perseverar en su ser por sí mismo, trataría de existir, a duras penas, en la mirada de los otros y tendría como único recurso la exhibición de sus asuntos privados en el centro del escenario. Y el espectador, individuo sin calidades y sin gravedad, se nutriría de su sola proyección en la vida de los otros. Mas, generalmente, los comentarios no son escasos para denunciar un nuevo narcisismo, estado último de la actitud individualista, que, ligado a la extrema potencia de las nuevas figuras del capitalismo, encontraría un terreno privilegiado en el marco definido por la evolución espectatorial de la sociedad ${ }^{8}$.

En el campo de la historia y de la teoría del arte, esos argumentos pueden ser tomados para evaluar una parte de la producción artística reciente, como hace, por ejemplo, Dominique Baqué en su libro Pour un nouvel art politique. De l'art contemporain au documentaire (2004). La autora ve en el interés declarado de los artistas por la micro-historia el equivalente de una actitud de desentendimiento fundado en las mitologías ingenuas de la veracidad de la emoción y sobre la ilusión de un auto-engendramiento del sujeto por sí mismo, al margen de los códigos sociales, de los formatos culturales y de las amenazas del mundo. En resumidas cuentas, estaríamos frente a proposiciones más acá de lo político, incapaces de desarrollar actitudes de resistencia, sintomáticas de un intimismo neurótico que hacen de pequeños secretos familiares y intimidad gástrica — según la expresión sartriana - la materia del arte. Ejemplo de esta orientación, según Baqué, serían los vídeos de Rébecca Bournigault que, adoptando la forma de un diario, muestran a la artista en su cama, al levantarse, o expresando sus frívolos e inmediatos deseos del momento.

${ }^{8}$ Ejemplo de este tipo de argumentación es el artículo de Séverine Lebert "Qui veut la peau de l'écorché vif ?", publicado online (2011) en una recopilación titulada L'art de l'intime. 


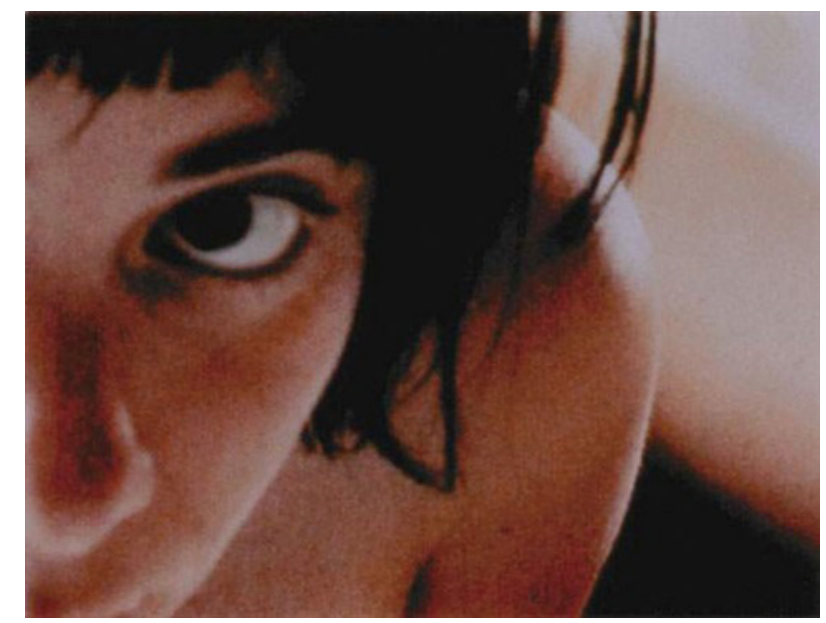

Figura 1. Rébecca Bournigault (1970-), Nu, 1999. Fotografía en color, 76 x $100 \mathrm{~cm}$.

\section{DE LO ÍNTIMO AL MUNDO COMÚN}

Vale la pena tratar de resistirse a esta poderosa y tentadora corriente argumentativa y hacerlo desde la perspectiva de la creación artística, ya que ella ocupa, por definición, una situación distanciada, un espacio donde es posible adoptar una posición crítica. En este campo, sin embargo, poco pesan las interpretaciones generales frente a las realidades singulares: el único método consiste en apoderarse de observaciones precisas. Así, partiendo de algunos ejemplos, queremos demostrar en primer lugar que el arte de lo íntimo en los últimos decenios no está necesariamente carente de toda dimensión política y, en segundo lugar, que tomar como material creativo la micro-historia no impide interrogar a la Historia. En este artículo examinaremos solo dos ejemplos que nos parecen suficientemente concluyentes.

Con The ballad of Sexual Dependency, la artista norteamericana Nan Goldin (1953-) fue una de las primeras en juzgar que lo íntimo y lo cotidiano podían constituir una materia artística. Su proyecto, descrito como una estrategia de supervivencia, era el de fotografiar su mundo, tal cual, sin ninguna censura, un mundo muy marginal, correspondiente a 
la familia afectiva que había escogido, huyendo de su familia biológica, caracterizada como rígida y agobiante. Durante 15 años, de 1981 a 1996, Goldin captó el regocijo y la miseria de los cuerpos, la exaltación sexual y la confusión de géneros, el brillo de la fiesta y la sombra de la muerte, o sea, los últimos fuegos de una generación que había conocido el placer libertario antes de que el frío glacial del SIDA se hubiera abatido contra ella. La obra está actualmente compuesta por casi 900 diapositivas que son proyectadas en bucle con una banda sonora muy heterogénea (James Brown, María Callas, The Velvet Underground) a la cual se superpone el chasquido regular del carrusel que acompaña el cambio de una imagen a otra. El conjunto constituye un testimonio sobre una vida errante en un universo lleno de violencia y poblado de individuos al margen de las normas y las leyes sociales: prostitutas, drag queens, toxicómanos... Nan Goldin se incluye ella misma en el grupo, no dudando en mostrar su decadencia física, su adicción a las drogas, su sumisión afectiva. La mayor parte de las fotografías son tomadas en dormitorios ordinarios y a veces sórdidos, cuyas camas, que muestran sábanas revueltas y un tanto andrajosas, forman el decorado principal. Pero sería inapropiado clasificar a Nan Goldin de complaciente: lejos de esto, ella elabora un retrato, sin maquillaje ni adornos, de lo que está fuera del cuadro idealizado de la vida americana.

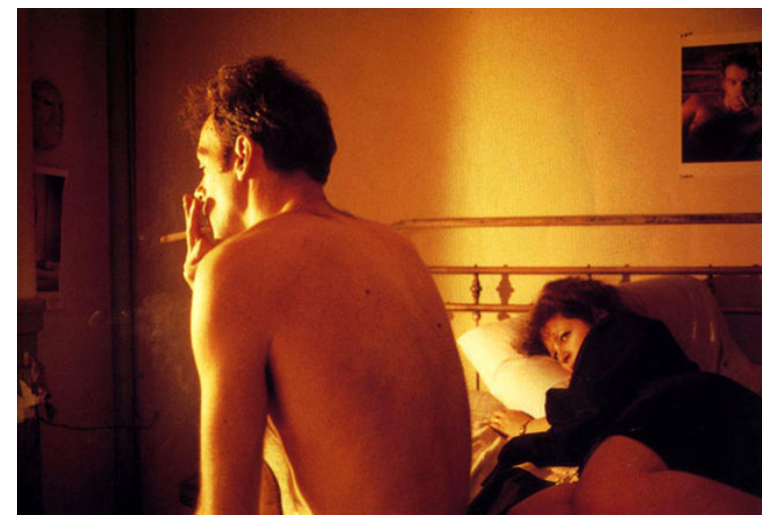

Figura 2. Nan Goldin, Nan y Brian in bed, 1983 (diapositiva).

"Yo creo en la intimidad, pero pienso que la gente protege erróneamente ciertas cosas como la sexualidad y la vergüenza que se vinculan con ella", afirma la artista. Frecuentemente, seguimos la lógica 
que nos induce a disociar espacio íntimo y espacio público, pensando que lo que se refiere a nuestros sentimientos, nuestras decisiones, reflexiones, posturas y actitudes propias corresponde solo a la libertad o la ética individual. Nos es difícil aceptar que estas obedecen a normas y códigos, maneras de pensar y de sentir, más o menos institucionalizados que las trascienden y contribuyen a establecer unas fronteras entre lo permitido y lo prohibido, lo visible y lo invisible, lo aceptable y lo inaceptable. En realidad, lo que llamamos lo íntimo pertenece plenamente al campo colectivo, como mostraron de forma ejemplar las reivindicaciones feministas en los años $60 \mathrm{y}$ atestiguan hoy en día la lucha LGBT para el reconocimiento de las identidades de género y las orientaciones sexuales desconocidas. El esfuerzo para llevar al terreno común lo que antes se pensaba puramente personal no es el resultado de una pulsión exhibicionista, sino de la comprensión de que la puesta en escena de lo íntimo es condición del avance de la igualdad y de aceptación de las diferencias. En este sentido, no se puede negar la dimensión sociológica, pero también eminentemente política, del trabajo de Nan Goldin que, ciertamente, plantea cuestiones individuales e íntimas, pero con una formulación general. ¿Cómo se tejen los lazos entre los individuos? ¿Qué es la sumisión libremente consentida? ¿Cómo se asume la propia diferencia?

\section{PEQUEÑA Y GRAN HISTORIA}

Algunas proposiciones artísticas se esfuerzan por poner de relieve de modo más explícito la dimensión privada de la vida y las situaciones históricas que constituyen su telón de fondo. A esta categoría pertenece la colaboración de Yasmine Eid-Sabbagh y Rozenn Quéré titulada Vies possibles et imaginaires (2012). Se trata de un trabajo constituido por cien fotografías acompañadas de textos, que puede ser presentado bajo la forma de un libro o de una instalación ${ }^{9}$. El conjunto, que retrata los momentos de vida de cuatro hermanas palestino-libanesas (en realidad las tías de Yasmine Eid-Sabbagh), dispersas por los cuatro rincones del mundo, es representativo de un modo de narración que puede describirse como una reconfiguración de la historia familiar a partir de documentos extraídos de

${ }^{9}$ Fue presentado como instalación, por ejemplo, en el festival Images de Vevey en 2012 o en los encuentros fotográficos de Arles en 2013. 
álbumes fotográficos ${ }^{10}$.

La doble particularidad de la obra de Yasmine Eid-Sabbagh y de Rosenn Quéré estriba, por una parte, en poner en perspectiva una pequeña y al mismo tiempo gran historia - la guerra de Líbano-y, por otra, en dejar un amplio espacio a la imaginación, como indica el mismo título de la obra. La dimensión ficcional es, en principio, afirmada mediante la proyección de un futuro próximo: las fotografías están ordenadas para formar un relato que se desarrolla desde 1943 hasta 2022, año en el cual una de las protagonistas, Graziella, tendrá 82 años. Las hermanas parecen estar presas en el movimiento de un exilio permanente que les ha hecho pasar por Italia, Canadá, Egipto, Francia, Inglaterra y también Líbano, Palestina y Estados Unidos. Las temporalidades heterogéneas se entrechocan, de lo que surgen motivos que no revelarían un relato lineal. A estas confusiones se añade el retoque de las fotografías: se agregan personajes ausentes, por incrustación o sobreimpresión; otros, al contrario, son borrados y solo subsiste su silueta. Detrás de las imágenes, hay otras remanentes que actúan como resonancia de aquellas y suscribirían el comentario de G. Didi-Huberman (2008: 12): "Frente a una imagen, no hay que preguntarse solo qué historia documenta y de qué historia es contemporánea, sino también: qué historia se construye, de qué contraflujo nos retorna"11.

${ }^{10}$ Este tipo de narración es frecuente en la última década, como muestran, por ejemplo, las series Imagine finding me (1982-2012) de Chino Otsuka o Photos souvenirs (2009) de Carole Benitah. ${ }^{11} \mathrm{La}$ traducción es nuestra. 


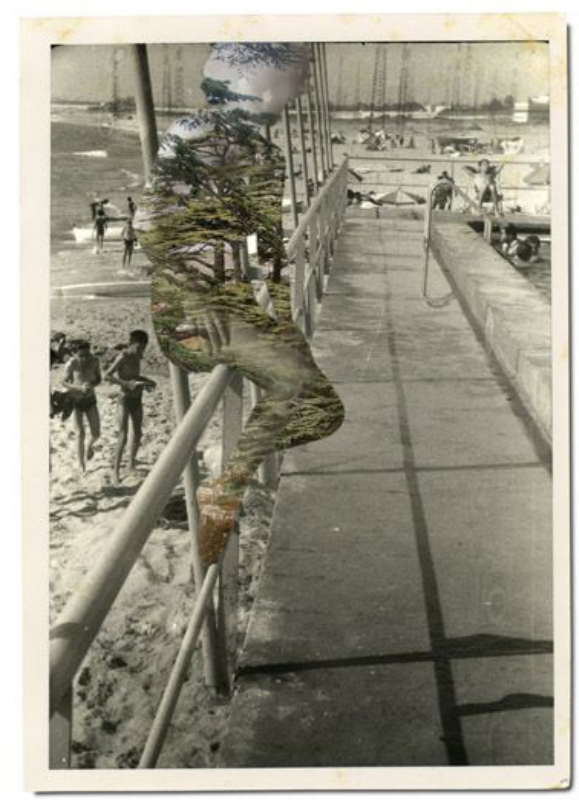

Figura 3. Yasmine Eid-Sabbagh y de Rosenn Quéré, Vies possibles et imaginaires. Fotografía, 2012.

La obra de las dos artistas es un verdadero montaje que permite a la memoria escondida salir a la superficie. Lo íntimo refleja una experiencia familiar que permanece fluctuante y termina de constituirse en el presente. A través de las remembranzas, las reconstrucciones y las invenciones, el otro (que es también un ser cercano) es aprehendido no solo por lo que ha hecho y vivido, sino por lo que hubiera podido hacer y vivir. No es cuestión aquí, como en La Chambre claire de Roland Barthes, de lanzarse a la búsqueda de la única fotografía que restituiría la esencia de las personas ${ }^{12}$. La verdadera imagen no existe y solo se pueden presentar fragmentos que expresan facetas sin formar una unidad. No hay pacto de sinceridad ni

\footnotetext{
${ }^{12}$ Hacemos aquí referencia a la búsqueda por parte del autor de una fotografia de su madre muerta que restituiría lo que de verdad era ella. Esta búsqueda se superpone a la de la esencia de la fotografía, que constituye el pretexto teórico del libro. Barthes encuentra finalmente una fotografia de su madre, tomada en un jardín de invierno cuando ella tenía cinco años, foto que parecía satisfacer sus pretensiones: la describe, pero no la reproduce (Barthes, 1980).
} 
espíritu de verdad que valgan aquí.

Al mismo tiempo que los historiadores encuentran en los archivos familiares, que mucho tiempo fueron desatendidos, una documentación de primer interés, algunos artistas actuales descubren que pueden utilizar las reliquias familiares como material de sus obras. Pero a diferencia de los primeros, no tratan de acercarse a la verdad de los eventos históricos apoyándose en la intensidad de lo vivido, sino que toman como punto de partida la disolución de lo real, que se manifiesta en un juego de espejos. Manipulan así los documentos y las imágenes porque entienden que todo es relato y que lo íntimo, según $\mathrm{H}$. Arendt, toma forma solamente a través de un acto de configuración narrativa. A veces el relato propuesto incluye una parte imaginaria explícita (Yasmine Eid-Sabbagh y Rosenn Quéré), otras, al contrario, asume la apariencia cruda de una experiencia restituida sin ningún filtro (Nan Goldin). Más allá todavía, algunos artistas parecen haber renunciado al deseo mismo de realizar una obra, contentándose con la restitución plana de la banalidad de sus vidas (Rébecca Bournigault). La creación artística, finalizando el largo proceso de desublimación iniciado con la modernidad, juega entonces con la decepción del espectador. Al hacerlo, responde a la paradoja estética de lo infra-ordinario destacada por Georges Perec:

Lo que ocurre en realidad, lo que vivimos, lo demás, todo lo demás ¿dónde se encuentra? Lo que ocurre cada día y que se repite cada día, lo banal, lo cotidiano, lo evidente, lo común, lo ordinario, lo infra-ordinario, el ruido de fondo, lo habitual, ¿cómo dar cuenta de eso, cómo interrogarlo, cómo describirlo ? (Perec, 1989: 11) ${ }^{13}$.

Si lo que verdaderamente importa es lo que se vive sin heroísmo en lo cotidiano ¿cómo evitar la banalidad de su transcripción? Del mismo modo que tenemos que renunciar a la idea de que lo más interior oculte algún secreto (Mona Hatoum), es muy probable que debamos aceptar que lo íntimo, sin existencia fuera de la posibilitad de su comunicación (Arendt), sea también lo más común, o sea, lo más compartido y ordinario.

${ }^{13} \mathrm{La}$ traducción es nuestra. 


\section{REFERENCIAS BIBLIOGRÁFICAS}

ARENDT, H. (1961). Condition de l'homme moderne [trad. francesa de Georges Fradier]. Paris: Calmann-Lévy.

BAQUÉ, D. (2004). Pour un nouvel art politique. De l'art contemporain au documentaire. Paris: Flammarion.

BARTHES, R. (1980). La Chambre claire. Note sur la photographie. Paris: Cahiers du cinéma / Gallimard / Seuil.

CAUQUELIN, A. (2003). L'Exposition de soi. Du journal intime aux Webcams. Paris: Eshel.

CHIRON, E. et LELIÈVRE, A. (ed.) (2012). L'intime, le public, le privé dans l'art contemporain. Paris: Éditions de la Sorbonne.

DIDI-HUBERMAN, G. (2008). "La condition des images" [entrevista con F. Lambert y F. Nine]. MediaMorphoses 22, 6-12, http://hdl. handle.net/2042/28239 [06/02/2019].

LEBERT, S. (2011). “Qui veut la peau de l'écorché vif ?”. En L'art de l'intime, Sylvie Servoise (dir.), http://www.raison-publique.fr/ article414.html [06/02/2019].

LEBOVICI, E. (ed.) (2004). L'Intime. Paris: ENSBA.

LIPOVETSKY, G. (1983). L'Ėre du vide, Essais sur l'individualisme contemporain. Paris: Gallimard.

MAISON ROUGE, I. de (2004). Mythologies personnelles. L'art contemporain et l'intime. Lyon: Scala.

MELMAN, C. (2002). L'Homme sans gravité. Jouir à tout prix. Paris: Denoël.

PEREC, G. (1989). L'Infra-ordinaire. Paris: Seuil.

THÉLY, N. (2002). Vu à la web-cam (essais sur la web-intimité). Dijon: Les Presses du Réel.

TISSERON, S. (2001). L'Intimité surexposée. Paris: Ramsay.

WATTEAU, D. (ed.) (2010). Vivre l'intime (en el arte contemporáneo). Paris: Thalia.

Recibido el 5 de abril de 2019.

Aceptado el 3 de junio de 2019. 